\title{
Pattern of Intervention in Congenital Heart Disease: Single Centre Analysis of Cases over Five Years in Bangladesh
}

Begum NNF ${ }^{1}$, Bhuiyan $\mathrm{NI}^{2}$, Khan $\mathrm{AA}^{3}$, Alam $\mathrm{MJ}^{4}$

DOI: https://doi.org/10.3329/jafmc.v15i1.48630

\begin{abstract}
Introduction: In Bangladesh, 25/1000 cases of neonates are born with mild to severe type of congenital heart disease. Significant numbers of cases from new born to adult age group are reporting to OPD clinics with broad spectrum of congenital and grown up untreated heart diseases. This study will cover pattern of diseases among cases selected for cardiac catheterization and intervention in study group in a cardiac hospital with limited facility for children.
\end{abstract}

Objectives: To analyze all the cases who had cardiac catheterization and intervention in said period and to see the outcome.

Materials and Methods: It is a retrospective study conducted in a cardiac hospital from December 2014 to December 2019. All cases of cardiac catheterization and interventions were included in the study. Pattern of diseases, interventions, management and outcomes were analyzed.

Results: Out of 1179 cases, $44.87 \%$ were male and $55.13 \%$ were female. Two hundred fifty four cases(21.54\%) were in 0-1 year age group, $44.02 \%$ were in $>01-05$ year age group, $18.66 \%$ cases were in $>5$ to 10 year , $8.48 \%$ cases were in $>10$ to 20 years, $4.83 \%$ cases were in> 20 to 30 years and $2.46 \%$ cases were in more than 30 year age group. Among trans-catheter closure patent ductus arteriosus (PDA) was the commonest type of intervention (44.68\%), followed by atrial septal defect (ASD) (25.20\%), ventricular septal defect (VSD) (11.83\%) and balloon valvoplasty (BVP) for pulmonary stenosis (11.63\%). Neonatal interventions were minimum as the coronary care unit used as post cathward had limited facility for neonatal care. PDA stenting was performed in $0.81 \%$ cases and BAS in $0.91 \%$ cases. Many patients underwent more than one intervention at a time; most common was ASD device closure and pulmonary valvoplasty. Cardiac Catheterization studies were minimum in this series and most of the cath study cases were VSD or/with other combinations (4.48\%). Among infants (254), PDA device closure was the commonest intervention (64.56\%) followed balloon valvoplasty for PS (15.35\%) and balloon dilation of Coarctation on aorta (7.87\%). Among implants, most commonly used were $8 / 6 \mathrm{~mm}(14.59 \%)$ Amplatzer Duct occluder (ADO), 6/4 ADOII, MF-Konar (9.79\%) device and most common balloon used for valve or vessel dilation was $10 \times 3 \mathrm{~mm}$ Tyshak II (3.26\%). Only one mortality was noticed in a case of double intervention of critical Aortic and pulmonary valve stenosis.

Conclusion: Commonest and established interventions were performed in this study other than few life saving interventions in neonates and outcome was excellent. Skilled team of pediatric cardiologist and technician in catheterization laboratory can bring success at the end of the day in spite of challenges.

Key-words: Congenital heart disease, Intervention pattern, Outcome.

\section{Introduction}

Incidence of congenital heart disease is 6-8/1000 live birth if only moderate to severe categories are included ${ }^{1}$. In Bangladesh, a study conducted among hospital live birth showed incidence of $25 / 1000$ which included mild form of diseases also ${ }^{2}$. As a result of continuous medical education programs, delay in detection of disease by pediatrician, delayed referral, delay in identification by parents is significantly reduced over the years ${ }^{3}$. Social media and internet connectivity in rural areas enabled parents to notify any kind of abnormalities in their children in earliest possible chance. Even many parents from rural area can search in Google search engine for a perfect physician for their child. So there is a shift of reporting time of patient with congenital heart disease towards early infancy ${ }^{2}$. Interventions are also performed in newborn period and in early infancy for various diseases as smaller size hardware are now available in the market for this group of patients ${ }^{4}$. As a developing country, we have no manufacturer of hardware and all intervention related works and implants are import dependent. As a result we often choose off-label devices and implants in many interventions specially in some occasion of bailing out from complications. Later we found them as good alternative and used as routine procedure. In view of many limitations as resource constraint set up, this study was conducted in a make shift adult catheterization laboratory of a cardiac hospital where facility for pediatric intervention was very limited. Outcome were compiled and analyzed.

\section{Materials and Methods}

It was a retrospective observational study conducted in Lab Aid Cardiac Hospital of Bangladesh. Catheterization laboratory of this hospital was an adult lab but pediatric facilities were arranged for pediatric cardiac team of another hospital to reduce waiting

1. Brig Gen Nurun Nahar Fatema Begum, SBP, MBBS, FCPS, FRCP, FACC, FSCAI, Independence Awardee, Professor \& Head, Department of Paediatrics, Armed Forces Medical College, Dhaka, (E-mail: colfatema@hotmail.com) 2. Lt Col Nazmul Islam Bhuiyan, MBBS, FCPS, Classified Specialist in Paediatrics, CMH, Dhaka 3. Lt Col Md. Ashfaque Ahemmed Khan, MBBS, DCH, FCPS, Classified Specialist in Paediatrics, CMH, Dhaka 4. Lt Col Md. Jahangir Alam, MBBS, DCH, FCPS, Classified Specialist in Paediatrics, $\mathrm{CMH}$, Dhaka. 
list of the patients in first hospital. So routine cases were usually selected for this lab, few cases of emergency interventions were also performed when situation demanded. All cases who had cardiac catheterization or interventions were included in the study. In some cases, device implantation were postponed and included in diagnostic catheterization group. All cases had preoperative check up with physical examination, blood work up, CXR, ECG and Echocardiography. Echocardiography was usually performed thoroughly on day before procedure to plan strategy of intervention and to determine the size of the devices, balloons, stents etc. Cath lab staffs were informed one day prior to procedure about the probable need of hard ware and implants. Various suppliers were also informed to make the disposables and implants available as stock was limited in that lab. Patients were kept nothing per oral for four hours prior to procedure. Blood bank kept stand by for any need. Anesthesia coverage was standing by for newborn and young infants in all cases. We preferred cocktail sedation with injection Midazolum, Ketamine, Phenobarbitone rather than general anesthesia for all children up to 10 years. Older children and few non-cooperative adults were sedated with injection Midazolum alone. General anesthesia was given in only two cases for respiratory arrest.

During procedure, trans-thoracic echo guide and fluoroscopy guide were used for all interventions. Trans-oesophageal echo was not required. Injection ceftriaxone $50 \mathrm{mg} / \mathrm{kg}$ body weight was used in all cases for 48 hours. Pressure bandage was loosened after 04 hours and removed after 24 hours. Aspirin was advised in ASD device cases for 06 month, VSD device cases for 03 months and stent cases till next surgery. All patients were discharged after 24 hours observation other than cases of PDA and RVOT stenting, these cases had heparin infusion for 72 hours and then discharged with Aspirin. Echocardiography was performed in every case before discharge. Follow up was given at 1, 3, 6, 12, 18, 24 months and yearly thereafter for three years for completely cured cases. In every follow up echocardiography was always performed, CXR and ECG were occasionally performed. Data were collected from computerized data record of the pediatric catheterization and, Echo laboratory and were analyzed manually in term of frequency and median. Informed consent was taken from every parents and adult patients as per Helsinki declaration and permission from concerned ethical committee obtained. Statistical analysis: Numerical and categorical data were expressed in number and frequencies. MS Excel spread sheet was used for analysis. As it is a single variant data, comparative tests were not done.

\section{Results}

Out of 1179 cases, 980(83\%) cases had successful intervention, $146(12 \%)$ cases had diagnostic catheterization and $53(5 \%)$ cases had trial of various device closures and postponed (Figure-1).

Age of the patient varied from neonate to adults. Infants were $254(21.54 \%)$, up to 05 years were $519(44.02 \%)$, up to 10 years were $220(18.66 \%)$, up to 20 years were $100(8.48 \%)$, up to 30 years were $57(4.83 \%)$ and more than 30 years were $29(2.46 \%)$, lowest age was 02 days and highest age was 65years. Median age was 3 years. Male were $529(44.87 \%)$ and Female were $650(55.13 \%)$. Male and female ratio was 1:1.22 (Table-I). Out of total $980(100 \%)$ cases, 386(39.38\%) cases had PDA device closure, 52(5.31\%) cases had PDA coil occlusion, total PDA closure was $438(44.68 \%)$, $247(25.20 \%)$ had ASD closure,116(11.84 \%) cases had VSD closure, 114(11.63\%) cases had BVP for PS, 37(3.78\%) cases had balloon coarctoplasty, $9(0.91 \%)$ cases had BAS, $4(0.40 \%)$ cases had BVP for AS, $8(0.81 \%)$ cases had PDA stenting, $2(0.20 \%)$ had RVOT stenting, $4(0.40 \%)$ cases had RPA and LPA balloon angioplasty and one $(0.10 \%)$ had closure of AV fistula with arteriovenous plug (AVP) (Figure-2).

Out of 450 PDA cases, 386(39.38\%) had device closure, $52(5.31 \%)$ had coil occlusion, $8(1.77 \%)$ cases had cath study, 3 devices were embolized (one retrieved and cook coil reimplanted) and 4 cases were referred to cardiac surgeon (2 from cath study for huge size and two for embolization to RPA and retrieval was failed) (Figure-3). Out of 286 ASD secundum cases, 247(86.36\%) cases had device closure $12(4.19 \%)$ cases had cath study and $27(9.44 \%)$ cases had trial of device closure but failed due to deficient aortic rim.. Thirty Five cases were referred to cardiac surgeon and two were inoperable, other two kept on follow up for another trial in future. Three devices were embolized in post cath observation time and were sent to operation theatre (Figure-4). Out of 160 VSD cases $116(72.55 \%)$ had device closure. Device trial postponed in $26(12.5 \%)$ cases, cath study performed in $18(11.15 \%)$ cases, 30 cases were referred to cardiac surgeon and 12 were kept in follow up, two cases were found inoperable from cath study. No devices were embolized (Figure-5). Regarding combined intervention in single patient, most common double intervention was ASD device closure and BVP for PS , performed in $8(0.8 \%)$ followed by ASD and PDA device closure in $3(0.3 \%)$ cases, PDA device closure and aortic BVP in $2(0.2 \%)$, PDA coil occlusion and BVP PS in 2(0.2\%), PDA device closure and RPA and LPA balloon valvoplasty in $2(0.2 \%)$, LPA and RPA balloon valvoplasty in $2(0.2 \%)$ cases (Figure-6).

Out of 254 infants cases, 170(66.92\%) cases had PDA device closure, 39(15.35\%) cases had BVP for critical PS, 20(7.87\%) had balloon coarctoplasty, $6(2.36 \%)$ had ASD device closure. ASD device closure was performed early for rapid increment of size of ASD secundum in subsequent follow up (Table-II). Various implants used in study cases were septal occluder in 247(25.20\%), ADO II and MF-Konar in 112(11.42\%), duct occluder for PDA 386(39.38\%), Tyshak and Z-med balloon of various size in $122(12.44 \%)$, PDA stent in $8(0.81 \%)$, balloon angioplasty for CoA $37(3.77 \%)$, Cook coil for VSD closure in $4(0.40 \%)$, Numed septostomy balloon in $9(0.91 \%)$ and others (AVP, peripheral stent) in $3(0.30 \%)$ (Table-III). Regarding diagnostic cases; ASD of different type was $52(4.41 \%)$. VSD of different type $53(4.49 \%)$, MA with association $2(0.16 \%)$, PA with association $9(0.76 \%)$, TA with association $2(0.16 \%)$, Infundibular stenosis $2(0.16 \%)$, hypoplastic right heart $1(0.08 \%)$, PDA $9(0.76 \%)$, TOF $22(1.86 \%)$, DORV, VSD, PS 5(0.42\%), D-TGA 5(0.42\%), C-TGA $4(0.33 \%)$ AV canal $5(0.42 \%)$, DILV $2(0.16 \%)$, AS, AR $4(0.33 \%)$, AP window, ALCAPA $3(0.25 \%)$ (Table-IV).

Regarding outcome of interventions; no mortality or other major complications were noticed in device closure cases, ASD and PDA device embolized in 03 cases each, one PDA device was retrieved and coil occlusion was performed. One double intervention case of combined AS and PS expired in post cath 
observation. Transient arrhythmia was observed in 12 cases of ASD but disappeared within 24 hours. Temporary pulse loss was observed in cases of femoral artery cannulation in small infants (2 in PDA stent, 4 in PDA device and 3 in coarctoplasty cases) but reappears with heparin infusion. Two cases of PDA device closure died after discharge from aspiration of milk (Table-V).

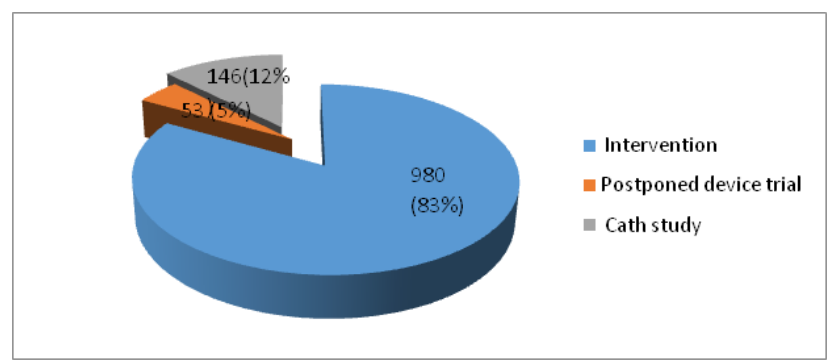

Figure-1: Type of study cases $(n=1179)$

Table-l: Age and sex distribution of patients $(n=1179)$

\begin{tabular}{|l|l|l|l|c|}
\hline \multirow{2}{*}{ Age in years } & \multirow{2}{*}{ Total } & \multicolumn{2}{|c|}{ Sex } & \multirow{2}{*}{$\begin{array}{c}\text { Male to female } \\
\text { ratio }\end{array}$} \\
\cline { 3 - 4 } & & \multicolumn{1}{|c|}{ Male } & \multicolumn{1}{|c|}{ Female } & \\
\hline $0-01$ & $254(21.54)$ & $119(46.9)$ & $135(53.1)$ & $1: 1.3$ \\
\hline$>01-05$ & $519(44.02)$ & $234(45.1)$ & $285(54.9)$ & $1: 1.2$ \\
\hline$>05-10$ & $220(18.65)$ & $99(45.0)$ & $121(55.0)$ & $1: 1.2$ \\
\hline$>10-20$ & $100(8.48)$ & 42() 42.0 & $58(58.0)$ & $1: 1.4$ \\
\hline$>20-30$ & $57(4.83)$ & $24(42.1)$ & $33(57.9)$ & $1: 1.4$ \\
\hline$>30$ & $29(2.45)$ & $11(37.9)$ & $18(62.1)$ & $1: 1.6$ \\
\hline Total & $1179(100)$ & $529(44.87)$ & $650(55.13)$ & $1: 1.2$ \\
\hline
\end{tabular}

Note: Percentage in parenthesis. Lowest age was 02 days, highest 65 years, median 03 years.

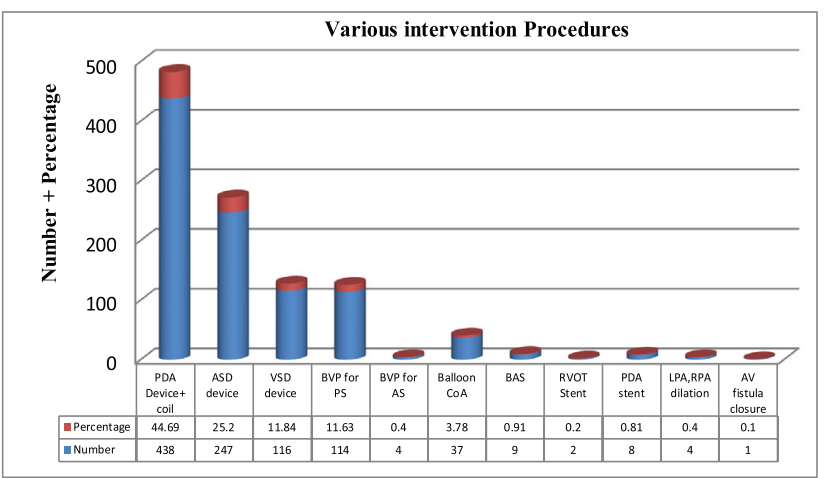

Figure-2: Various intervention procedures in study group $(n=980)$

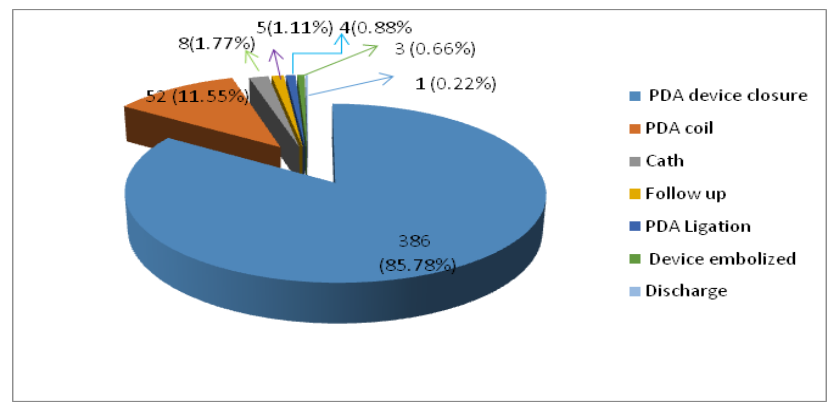

Figure-3: Summary of PDA cases $(n=450)$

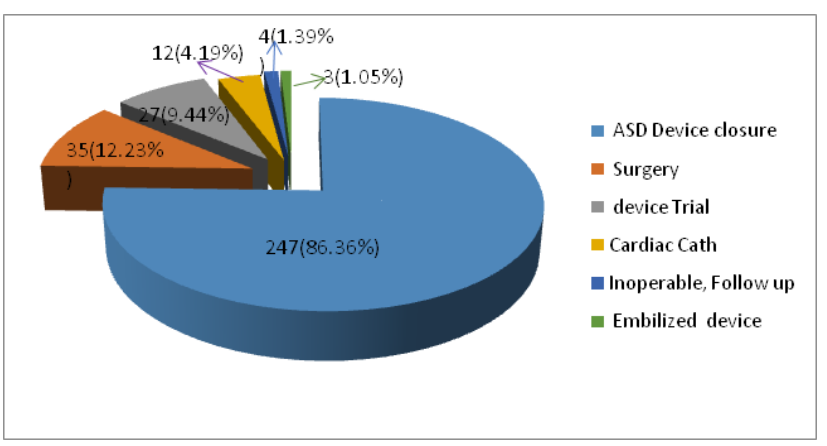

Figure-4: Summary of ASD secundum cases $(n=286)$

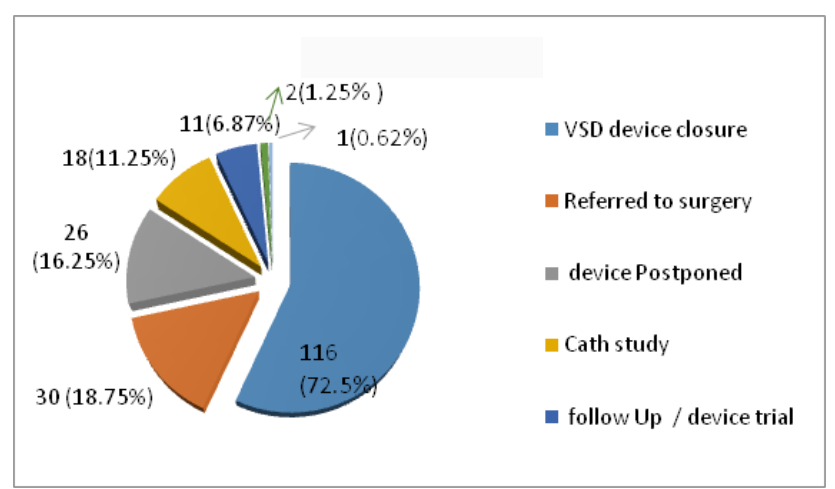

Figure-5: Summary of VSD cases $(n=160)$

Double Intervention

number $n$ Percentage

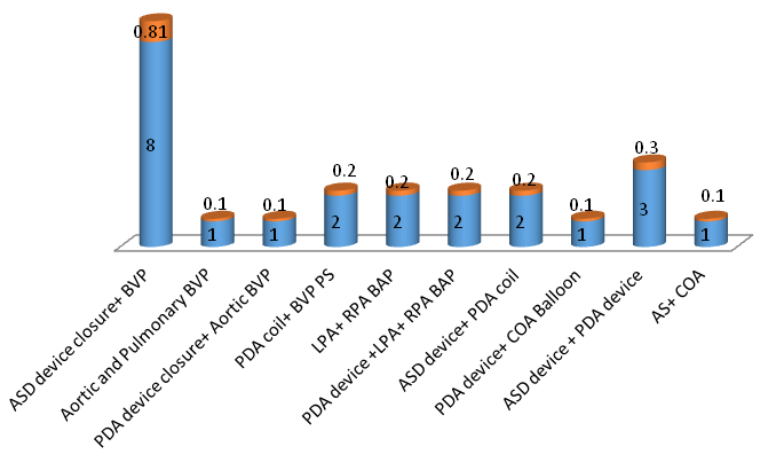

Figure-6: Double Intervention in study group $(n=23 / 980)$

Table-II: Pattern of diseases and interventiona in young infants $(n=254)$

\begin{tabular}{|l|l|c|}
\hline \multicolumn{1}{|c|}{ Disease } & \multicolumn{1}{c|}{ Management } & Number (\%) \\
\hline D-Tranposition of great arteries (DTGA) & Balloon Atrial Septostomy (BAS) & $08(3.54)$ \\
\hline Severe / Critical Coarctation of Aorta & Balloon Coarctoplasty & $20(7.87)$ \\
\hline Critical pulmonary valve stenosis & Balloon Valvoplasty & $39(15.35)$ \\
\hline PA ASD II, PDA & PDA stenting & $04(1.57)$ \\
\hline PA VSD,PDA & PDA stenting & $04(1.57)$ \\
\hline Patent Ductus Arteriosus (PDA) & PDA device closure/ coil occlusion & $170(66.93)$ \\
\hline Atrial septal defect secundum type & ASD device closure & $06(2.36)$ \\
\hline Hypoplastic right heart syndrome & PDA stenting posponed & $01(0.39 \%)$ \\
\hline Tetralogy of Fallot (TOF) & ICR & $01(0.39)$ \\
\hline Pulmonary atresia, PFO, SIP BT shunt & Balloon Atrial Septostomy & $01(0.39)$ \\
\hline
\end{tabular}


Table-III: Size of various implants used $(n=980)$

\begin{tabular}{|l|c|c|}
\hline \multicolumn{1}{|c|}{ Implants name } & Size in $\mathrm{mm} / \mathrm{ml}$ & Number (\%) \\
\hline Septal Occluder (ASO) & 12 to 40 & $247(25.20)$ \\
\hline ADOIl and MF-Konar for VSD & $6 / 4$ to $10 / 8$ & $112(11.42)$ \\
\hline Ductal occluder for PDA. & $6 / 4$ to $20 / 18$ & $386(39.38)$ \\
\hline Cook detachable Coil for PDA & $5 \times 3$ cook to $5 \times 4$ & $52(5.30)$ \\
\hline Tyshak II Balloon/ Andra balloon/Z-Med balloon & $6 \times 3$ to $22 \times 4$ & $122(12.44)$ \\
\hline PDA Stent (Coronary) & $3.0 \times 12$ to $4.0 \times 118$ & $8(0.81)$ \\
\hline Balloon angioplasty for CoA & $6 \times 3$ to $18 \times 4$ & $37(3.77)$ \\
\hline Cook coil for VSD & $5 \times 3$ & $4(0.40)$ \\
\hline Nuemed septostomy balloon & $2 \mathrm{ml}$ & $9(0.91)$ \\
\hline Others & AVP, Peripheral stent & $3(0.30)$ \\
\hline
\end{tabular}

Table-IV: Distribution of cases other than percutaneous intervention with management plan ( $n=199 / 1179)$

\begin{tabular}{|l|l|c|}
\hline \multicolumn{1}{|c|}{ Disease } & \multicolumn{1}{c|}{ Management Plan } & Number (\%) \\
\hline $\begin{array}{l}\text { ASD IIO, ASDI0, SV ASD } \pm \\
\text { PAPVD } \pm \text { TAPVD } \pm \text { PS }\end{array}$ & $\begin{array}{l}\text { ASD closure } \pm \text { Valvotomy } \pm \text { Rerouting } \\
\text { PAPVC, TAPVD, Follow up/ Inoperable }\end{array}$ & $52(4.41)$ \\
\hline $\begin{array}{l}\text { Sub aortic VSD } \pm \text { SAM } \pm \text { AR } \\
\pm \text { PM VSD } \pm \text { Inf. Stenosis }\end{array}$ & $\begin{array}{l}\text { VSD closure } \pm \text { AoVresuspension } \pm \text { SAM } \\
\text { Excision } \pm \text { Follow up/ inoperable }\end{array}$ & $53(4.49)$ \\
\hline MA, DORV, VSD \pm PHT \pm PS & Inoperable/ BDG & $02(0.16)$ \\
\hline PA VSD \pm ASD \pm PDA \pm MAPCA & Inoperable/ BT Shunt/ ICR & $09(0.76)$ \\
\hline TA, ASD, VSD \pm DORV, PS & PAB/ BDG & $02(0.16)$ \\
\hline Infundibular stenosis & Infundibular resection & $02(0.16)$ \\
\hline Hypo RT heart PS, PDA & BT Shunt & $01(0.08)$ \\
\hline PDA & PDA ligation /Follow up & $09(0.76)$ \\
\hline TOF/Dextrocardia & ICR & $22(1.86)$ \\
\hline DORV, VSD, PS & ICR & $05(0.42)$ \\
\hline DTGA, PFO & ASO & $05(0.42)$ \\
\hline C-TGA \pm PS \pm VSD & Follow up/ Senning + Rastelli & $04(0.33)$ \\
\hline COA supra AS/ COA/PDA & COA repair/ PDA ligation & $02(0.16)$ \\
\hline Truncusarteriosus & Rastellioperation & $02(0.16)$ \\
\hline DILV, DORV, PS, DTGA, BUP & BDG/ PA banding & $02(0.16)$ \\
\hline AV canal DORV, PS \pm TGA \pm & BDG/ Fontan completion/ Repair & $05(0.42)$ \\
BDG \pm PDA & + PDA ligation & \\
\hline RSOV (Ruptured sinus of valsalva) & Repair & $01(0.08)$ \\
\hline PA Sling & Surgery & $01(0.08)$ \\
\hline AS \pm AR & AVR /Ross & $04(0.33)$ \\
\hline AP window/and ALCAPA & Surgical correction & $03(0.25)$ \\
\hline Others & Follow up & $8(0.67)$ \\
\hline
\end{tabular}

Table-V: Outcome of intervention $(n=980)$

\begin{tabular}{|c|c|c|c|c|c|c|c|}
\hline Type of Intervention & \begin{tabular}{|l|} 
Total cases $\mathrm{n}(\%)$ \\
\end{tabular} & $\begin{array}{l}\text { Cured/ } \\
\text { successful } \\
\text { n(\%) }\end{array}$ & $\begin{array}{l}\text { Transient } \\
\text { arrhythmial } \\
\text { AV block }\end{array}$ & $\begin{array}{c}\text { Transient } \\
\text { Pulse loss/ } \\
\text { permanent } \\
\text { loss }\end{array}$ & \begin{tabular}{|c|} 
Embolized/ \\
retrieved \\
and closed
\end{tabular} & \begin{tabular}{|c|} 
Death \\
in Cath \\
lab \\
\end{tabular} & $\begin{array}{l}\text { Death in post cath } \\
\text { observation After } \\
\text { discharger }\end{array}$ \\
\hline ASD device closure & $247(25.20)$ & $247(100)$ & $12 / 0$ & $03 / 0$ & $\mathrm{Nil}$ & 0 & 0 \\
\hline VSD device closure & $116(11.83)$ & $116(100)$ & $02 / 0$ & 0 & Nil & 0 & 0 \\
\hline PDA device closure & $386(39.38)$ & $386(100)$ & 0 & $03 / 1$ & 4 & 0 & $\begin{array}{l}012 \text { (Aspiration } \\
\text { of milk) }\end{array}$ \\
\hline PDA coil occlusion & $52(5.30)$ & $52(100)$ & 0 & & Nil & 0 & 0 \\
\hline $\begin{array}{l}\text { Balloon dilation } \\
\text { (PS+AS) }\end{array}$ & $\begin{array}{c}(114+4) \\
(11.63+0.4)\end{array}$ & $117(99.2)$ & 0 & $\mathrm{~N} / \mathrm{A}$ & Nil & 0 & $\begin{array}{l}1 / 0 \text { ( double } \\
\text { intervention } \\
A S \text { and } P S \text { ) }\end{array}$ \\
\hline Coarctoplasty & $37(3.77)$ & $37(100)$ & 0 & & $3 / 0$ & 0 & 0 \\
\hline $\begin{array}{l}\text { Stenting (RVOT } \\
\text { and PDA) }\end{array}$ & $10(1.02)$ & $10(100)$ & 0 & Nil & $2 / 0$ & 0 & 0 \\
\hline
\end{tabular}

Abbreviations: PDA: Patent ductus arteriosus, BVP: Balloon Valvoplasty, ASD: Atrial Septal Defect, PS: Pulmonary Stenosis, VSD: Ventricular Septal Defect, AS: Aortic stenosis, RVOT: Right Ventricle of outflow tract, LPA: Left pulmonary artery, RPA: Right Pulmonary Artery, MA: Mitral atresia, PA: Pulmonary atresia, TA: Tricuspid atresia, TOF: Tetralogy of Fallot, AR: Aortic regurgitation, TAPVD: Total anomalous pulmonary venous drainage, PAPVD: partial anomalous pulmonary venous drainage, TGA: Transposition of great arteries, DORV: Double outlet right ventricle, ALCAPA: anomalous origin of left coronary artery from pulmonary artery, BAS: Balloon atrial septostomy, BVP: Balloon valvoplasty, MAPCA: Major aorto pulmonary collaterals, AVR: aortic valve replacemen , ASO: arterial switch operation, BDG: bidirectional glenn shunt, PAB: Pulmonary artery banding, BT shunt: Blalock Taussig shunt, ICR: Intra cardiac repair, FDA: Food and Drug administration.

\section{Discussion}

As significant number of patient starting from newborn to adults are reporting regularly with wide spectrum of congenital heart diseases, professionals and industry are trying relentlessly to innovate hardware friendly for interventions making more and more diseases and young infants amenable to intervention. Though investment in this industry is minimum and many devices remain off label with a best fit use, pediatric cardiologists are working hard with innovative ideas to help patient of congenital heart disease with best approach. Among all interventions PDA device closure is accepted as the first choice of therapy even in neonates ${ }^{3}$. Since the first experience of the transcatheter occlusion of PDA by Porstmann et al ${ }^{4}$ in 1967, technical improvements over the years have increased the proportion of patients who undergo successful transcatheter closure ${ }^{5,6}$.

Despite the advancement in the procedure, there are many problems during performance of transcatheter PDA closure in infants: relatively large sheath size for small vessels, stiffness of the delivery system with resultant hemodynamic instability during device deployment, risk of protrusion of the device into the aorta or pulmonary artery, poor anchoring or stability within the PDA, and difficult retrievability ${ }^{6}$. In spite of many limitations, large tubular PDA is closed with double disc devices, or by special technique even in small infants ${ }^{3}$. The first series of tanscatheter ASD closure was reported by Terry King and Noel Mills ${ }^{7}$ in 1975 . About $80 \%$ ASD secundum can be closed by transcatheter technique ${ }^{8,9}$. Even sinus venosus ASD are now closed with covered stent in few centres ${ }^{10}$. Many cardiologists innovated technique of closing large ASD secundum with deficient rims ${ }^{10}$. VSD device closure was started initially with closure of muscular device, but now with use of off label devices like ADO II and MFO, perimembranous VSD can be closed successfully if not suitable to classical one like Amplatzer PM device. In 1998, lock et al reported first VSD closure ${ }^{11-13}$. Balloon valvoplasty (BVP) of stenotic valves has successful history since 1982. First successful BVP was performed in children at that time and currently this intervention is benefitting over 25,000 patients a year worldwide ${ }^{14}$.

Balloon dilatation of coarctation of aorta and other vessels are in practice since initial experience ${ }^{15}$ in 1982 . Stenting of arterial duct has almost replaced BT shunt procedure though initial results 
were not good ${ }^{16}$. RVOT stenting is recently getting popularity as a palliative intervention in small infants with infundibular stenosis (TOF and DORV VSD PS) as an alternative to BT shunt and also as a bridge in symptomatic infants having high risk for early primary repair ${ }^{17}$. Transcatheter pulmonary valve has emerged also as a promising intervention for dysfunctional conduit ${ }^{18}$. Balloon atrial septostomy was the first ever intervention in history of $\mathrm{CHD}$ and was performed in 1966 to create ASD in a patient of transposition of great arteries ${ }^{19}$. It has enabled thousand of newborn to survive and make a bridge for next corrective surgery. Learning curve for device closure of PDA, ASD, VSD are quick. Many varieties of other interventions are added in the list gradually, so many pediatricians are choosing pediatric cardiology as specialty of choice, but challenges still existing with interventions in young infant and structural interventions in adolescents and adults.

This study was conducted in a catheterization laboratory which was working as back up support of the primary laboratory situated in another hospital. Team composed of interventional cardiologist and technicians were same but facilities in cath lab and post cath ward was meant for adults. So low risk cases were selected for this lab unless, there was any emergency. In this study PDA device closure were performed in young infant even with some ASD closure along with life saving balloon dilatation, so median age is less. Patient accepted in this lab were routine cases in most of the time and sometimes few emergency and diagnostic studies were included when there was no schedule in the primary lab. So neonatal interventions and diagnostic catheterizations were minimum (83\% intervention 12\% Cath study) (Figure-1). Age distribution (Table-l) in this study showed highest incidence in one to five years age group with median age of 03 years. In a study conducted in Quebec, Canada showed median age of 11 years in their study populations ${ }^{20,21}$. In this study male were $44.87 \%$ and female $55.13 \%$ which does not correlate with Quebec study. In this study female were more as number of PDA and ASD device closure was high. Analysis of intervention pattern showed (Figure-2) PDA closure (44.68\%) was the highest intervention followed by ASD $(25.20 \%)$, VSD (11.83\%), PS (11.63\%), COA (3.77 \%) etc. Individual interventions will be discussed as per frequency.

PDA Device Closure: PDA closure procedure was the highest (44.68\%) of all intervention in this series. In May 2003 Amplatzer duct occluder (ADO) got approval and since then all large PDA's even tubular one are being closed with devices ${ }^{20}$. In Bangladeshi children, incidence of large tubular PDA is very high infants usually present with severe pulmonary hypertension or with heart failure, in some case there was right to left shunt also. So whatever was the body weight, all cases were accepted for PDA closure with innovation of Amplatzer duct occluder II (ADOII) and multifunctional occluder (MF-Konar), delivery system was minimum in size and even in this series we used coronary guide catheter of $5 \mathrm{~F}$ size to deploy newer devices. Result of PDA closure was surprising and echo after 24 hours of deployment showed reduction of pulmonary artery pressure dramatically. Three cases had embolization, two of them were referred to cardiac surgeon as retrieval was not possible and another retrieved and closed with a coil. Two patient aging 4 month and 13 month expired after discharge from hospital due to aspiration of milk. Two cases were postponed for very large size and low body weight (Figure-3).
ASD Device Closure: Out of 980 cases of successful intervention, $25.2 \%$ were ASD closure. Age group varied from 10 months to 65 years. In twenty seven cases device closure was tried but postponed for deficient rimsspecially aortic rim. In young children, it was noticed that, in some cases of the ASD secundum,size increases gradually in subsequent follow up. In those cases we performed early device closure to avoid surgical closure in future $^{1}$. In many studiescardiac perforation is a concern, but we are fortunate to have none since $2000^{21}$. Possible reason was balloon sizing in all cases to avoid oversized device. In present and previous series there was no history of erosion and complete heart block ${ }^{22}$. It was observed that success rate of device closure is more in children than adults and rim of children are more supportive $^{3}$. In this series total ASD secundumcases were 288 , $88.45 \%$ had device closure, $4.16 \%$ had cath study for pulmonary hypertension specially in adult cases and device postponed after trial in 27 cases. As a result 35 (12.15\%) cases were referred for surgical closure which was similar to other studies ${ }^{9}$ (Figure- 4).

VSD device closure: Muscular VSD device was the first kind of VSD (MVSD-O) device approved by the FDA, later perimembranous VSD (PM VSD-O) device came in use ${ }^{23}$. With innovation of ADOII, MF-Konar, large number of VSD's are now closed with these devices. In 2012, we started doing VSD device closure by retrograde approach using ADOII. First case was performed to fulfill request of a female patient of 35 years who refused to undergone surgical closure of subaortic VSD. It was performed only in 15 minutes. This success encouraged the operator to repeat in subsequent cases. Since 2018 we are using MF-Konar which is available in larger size and delivery system is small, we use Judkins right coronary guiding catheter in most of the cases. In this series we had total 160 cases of VSD, 72.5\% had device closure, procedure was postponed in $12.5 \%$ cases due to aortic regurgitation or persistent arrhythmia (Figure-5).

Balloon Valvoplasty for Pulmonary Stenosis: Since it is one of the simple pediatric cardiac interventions it was in practice ${ }^{4}$ since 1982. But critical pulmonary stenosis in neonates and young infants are high risk procedure and often life saving. In this series pulmonary valvoplasty cases were 114 of which 39 were less than one year of age (Figure-2).

Balloon Coarctoplasty: Though balloon angioplasty for native coarctation of aorta is controversial, we are practicing ${ }^{13,23}$ it since 1999. As pediatric cardiology was started in Bangladesh in 1998, there was scarcity of surgeon and we encouraged neonatal balloon angioplasty as a life saving procedure ${ }^{24,25}$. Result was excellent. No mortality, pulse loss from femoral artery cannulation and aneurysm formation encouraged author, to adopt it as first choice therapy. In this series 37 cases had coarctoplasty out of which 20 cases were young infant (Figure-2). In many cases more than one lesion were present which were amenable to intervention (Figure-6). Most common was combination ASD closure and balloon valvoplasty of PS. In another study, conducted by author on combined intervention had highest ASD and PDA closure ${ }^{26}$.

Interventions in Infants: Out of 254 cases of infants, 35 cases were newborn. Procedure performed in newborn were BAS, PDA stenting, Balloon dilation of coarctation of aorta and pulmonary 
valve. This findings and outcome were like other studies ${ }^{27-33}$. Most common intervention in infants was PDA device or coil closure. It was performed in $170(66.93 \%)$ infants with success rate of $99.4 \%$, which is better than other studies conducted in infants ${ }^{34-36}$. This success in this series and in other encouraged us to perform this intervention even in newborn and also in large tubular PDAs of infants. We performed balloon angioplasty of coarctation in 20 cases with excellent outcome. They never showed reappearance of coarctation in follow up. This experience supported the fact that once good blood flow started through stenosed area, it continues to grow with somatic growth. Though there is controversy in many studies regarding angioplasty of native coarctation specially in newborn, this finding encouraged us to take this option as first choice therapy ${ }^{37-39}$.

ASD device closure was performed in 6 infants after an observation that they were increasing in size rapidly in subsequent follow up. Results of the procedure were excellent which correlate with study conducted in children less than 3 years of age ${ }^{40}$. Implant size and types were summarized in Table-III. Most commonly used ASD device was $18 \mathrm{~mm}$, PDA device was $8 / 6 \mathrm{~mm}$, VSD device was $6 / 4 \mathrm{~mm}$ and balloon was $10 / 3 \mathrm{~mm}$. All diagnostic cases who were operable were referred to surgeons after proper work up and planning (TableIV). Outcome of the intervention in this study was rewarding in spite of having many limitations in service of cath lab and post cath ward for infants and children (Table-V). One patient with severe aortic and pulmonary valve stenosis expired in this study in immediate postoperative period. He developed hypotension and bradycardia after procedure which could not be reversed. Tachyarrhythmia after twelve ASD and two VSD closure was managed in cath lab and post cath ward. Three devices were embolized in ASD and three in PDA cases. All three ASD cases were sent to operation theatre, two of the PDA devices were not retrievable and sent to operation theatre, third one retrieved and a coil was implanted. Outcome of this study correlate with other relevant studies ${ }^{1,3,22}$.

\section{Conclusion}

This retrospective study based on analysis of medical records showed excellent outcome of all kind of interventions. Many facilities in this lab were not meant for children but expert team of cardiologist, nurses and technicians converted the lab as standard pediatric interventional catheterization laboratory. This study recommends the need of specialized facility in catheterization laboratory for neonates and children and trained team of technician and nurses along with expert paediatric cardiologist as team leader which ultimately led to successful outcome. Meticulous case selection is of course an important indicator to determine the outcomes.

\section{References}

1. Fatema NN, RB Chowdhury, L Chowdhury. Incidence of congenital heart disease among hospital live birth in a tertiarycare hospital of Bangladesh. Cardiovascular Journal 2008; 1(1):14-20.

2. King TD, Thompson SL, Steiner $C$ et al. Secundum atrial septal defect: nonoperative closure during cardiac catheterization. JAMA 1976; 235:2506-9.

3. Fatema NN. Pattern of Congenital heart disease and treatment options in a Bangladeshi center: Analysis of 6914 cases from noninvasive cardiac laboratory. Cardiovascular journal 2017; 9(2):97-105.
4. Kumar SM, Subramanian V, Bijulal S et al. Percutaneous closure of a moderate to large tubular or elongated patent ductusarteriosus in children younger than 3 years: Is the ADO II appropriate? Pediatr Cardiol 2013; 34(7):1661-7.

5. Safaa Ali, Amel El Sisi. Transcatheter closure of patent ductusarteriosus in children weighing $10 \mathrm{~kg}$ or less: Initial experience at Sohag University Hospital. J Saudi Heart Assoc.2016 Apr; 28(2):95-100.

6. Masura J, Walsh GS, Nigam M, Khalilullah M, Transcatheter occlusion of patent ductusarteriosus by Rashkind umbrella device: Follow up results. Am Heart J 1994; 128:539-41.

7. Kenny DP, Hizazi ZM. Current status and future potential of tanscatheter interventions in congenital heart disease. Circulation Research 2017; 120(6):1015-26. DOl:https://doi.org/10.1161/ CIRCRESAHA. 116.309185.

8. Begum NNF, Razzaque AKM, Rahman MH. Acvtivities of a Paediatric Cardiac Catheterization Laboratory in a Tertiary Hospital: One Year experience. Chest \& Heart Journal 2008; 32(2):81-6.

9. Begum NNF. Short Intermediate and long term follow up of device closure of ASD, study on 1020 cases. Cardiovascular Journal 2015; 7(2):85-92.

10. Clasco V, Fortr MN, Byrne $\mathrm{N}$ et al. Interventional correction of sinus venosus atrial septal defect and partial anomalous pulmonary venous return, Procedured planning using 3D printed models. JACC cardiovasC Imaging 2018; 11:275-8.

11. Fu YC, Bass J, Amin Z etal. Transcatheter closure of Perimembranous ventricular septal defects using the New Amplatzer membranous VSD Occluder. J Am Coll Cardiol 2006; 47(2):319-25.

12. Begum NNF, Rahman M, lqbal SA et al. Device closure of Perimembranous Ventricular Septal Defect with Amplatzer VSD Occluder. Chest and Heart Journal 2006; 30(I):73-5.

13. Arora R, Trehan V, Thakur AK et al. Transcatheter closure of Muscular ventricular Septal defects. J Interv Cardiol 2004; 17(20):109-115.

14. Buchanan JW, Anderson JH, white RI. The first balloon valvoplastyan historical note. J vet intern Med 2002; 16(1):116-7.

15. Lock JE, Neimi BA, Burke $B$ et al. Transcatheter angiography of experimental aortic coarctation. Circulation 1982; 66:1280.

16. Akintuerk H, Mickel - Behnke I, Valeske K. Stenting of the arterial duct and banding of the Pulmonary arteries: Basis for combined Norwood stage I and II repair in hypo plastic left heart. Circulation 2002; 105(9):1099-103.

17. Sandoval JP, Chaturvedi RR, Benson $L$ et al. RVOT stenting in TOF infants with risk factor for early primary repair. Cardiovascular interventions 2016; 9(12):29-35. DOI: https://doi.org/10.1161/ CIRCINTERVENTIONS.116.003979

18. Cheathum JP, Hellenbrand WE, Zahn EM. Clinical and haemodynamic outcomes up to 7 years after transcatheter pulmonary valve replacement in the US melody valve investigational trial. Circulation 2015; 131:1960-70.

19. Boehm W, Enmel M, Sreeram N. Balloon Atrial Septostomy: History and Technique. Images pediatric cardio 2006; 8(1):8-14.

20. Hoffman JI, Kaplan S. The incidence of congenital heart disease. J AM coll Cardiology 2002; 39:1890-1900. 
21. Marelli AJ, Mackie AS, Ittu $R$ et al. Congenital heart disease in general population. Circulation 2007; 115(2):163-72.

22. McElhinney DB, Quartermain MD, Kenny D et al. Relative risk factors for cardiac erosion following transcatheter closure of atrial septal defects: A case-control study. Circulation 2016; 133(18):1738-46.

23. Meadows J, Forbess J, Michel-Behnke I et al. Matthias Sigler and Alan Nugent.Catheter-Based Interventions for Congenital Heart Disease. J Clin Exp Cardiolog 2012; S:8

24. Begum NNF, Hossain MR, Rahman SMM et al. Transcatheter cardiac interventions in adult with congenital heart disease: experience In a Bangladeshi centre. Cardiovasc J 2009; 2(1):61-5.

25. Sos T, Sniderman KW, Rettek-Sos B et al. Percutaneous transluminal dilatation of coarctation of thoracic aorta post morterm. Lancet 1979; 2:970-1.

26. Begum NNF. Multiple intervention in single setting; Report on cases over one year. Cardiovascular 2016; 9(1):36.

27. Begum NNF, Rahman SMM. A Case Report on Balloon angioplasty in Coarctation of Aorta. JAFMC 2003; volxxxzz: 95-98.

28. Begum NNF, Coarctation of aorta managed by Balloon Angioplasty. JAFMC 2010; 6(1):4-7.

29. Lawn JE, Cousens $S$, Zupan J. Four million neonatal deaths when? Where? Why? Lancet 2005; 365:891-900.

30. Changlani TD, Jose A, Sudhakar A. Outcomes of infants with prenatally diagnosed congenital heart disease delivered in a tertiary care pediatric cardiac facility. Indian Pediatr 2015; 52(10):852-6.
31. Pruetz JD, Carroll C, Trento LU. Outcomes of critical congenital heart disease requiring emergent neonatal cardiac intervention. Prenat Diagn 2014; 34(12):1127-32.

32. Mellander M. Diagnosis and management of life - threatening cardiac malformations in the newborn. Semin Fetal Neonatal Med 2013; 18:302-10.

33. Colaco SM, Karande T, Bobhate PR. Neonates with critical congenital heart defects: Impact of fetal diagnosis on immediate and short-term outcomes. Ann Pediatr Cardiol 2017; 10(2):126-30.

34. Fischer G, Stieh J, Uebing A et al. Transcatheter closure of persistent ductusarteriosus in infants using the Amplatzer duct occuluder. Heart 2001; 86(4):444-47.

35. Al -Ata J, Arfi AM, Hussain A et al. The efficacy and safety of the Amplatzer ductal occlude in young children and infants. Cardiol Young 2005; 15(3):279-85. .

36. Butera G, De Rosa G, Chessa M et al. Transcatheter closure of persistent ductusarteriosus with the Amplatzer duct occuluder in very young symptomatic Children. Heart 2004; 90(12):1467-70.

37. Singer MI, Rowen M, Dorsey TJ. Transluminal aortic balloon angioplasty for coarctation of the aorta in the newborn. Am Heart J 1982; 103:131-2.

38. Sperling DR, Dorsey TJ, Rowen M et al. Percutaneous transluminal angioplasty of congenital coarctation of the aorta. Am J Cardiol 1983; 51:562-4.

39. Lock JE, Bass JL, Amplatz $\mathrm{K}$ et al. Balloon dilation angioplasty of aortic coarctation in infants and children. Circulation 1983; 68:109-16.

40. Han Y, Zhang X, Zhang F. Trancatheter and intraoperative device closure of atrial septal defect in infants under 3 years of age. J Cardiothorac Surg 2020; 15(9):1-7. 